\title{
Percutaneous Nephrolithotomy under Spinal Anaesthesia
}

\author{
Ansari Abdul Salam*, Nizamani Bahram K and Memon SR \\ Department of Urology, Liaqat University of Medical and Health Science, Pakistan
}

Submission: December 30, 2015; Published: February 26, 2016

*Corresponding author: Ansari Abdul Salam, Department of Urology, Liaqat University of Medical and Health Science, Jamshoro Sindh, Pakistan, Email: abdulsalam_ansari@yahoo.com

\begin{abstract} (PCNL).

Objective: To Evaluate efficacy and safety Profile of Intrathecal anaesthesia for adult patients undergoing percutaneous nephrolithotomy

Patients and Method: This study has been conducted at urology department Liaqat University Hospital Jamshoro. From 1st November 2013 to 31st October 2014. Thirty male patients aged between 25 to 75 years were included in this study. All patients were given spinal anaesthesia to perform PCNL. The height of block was assessed in all patients, any supplemental drug given was recorded in every case.

Results: There were thirty male patients in this study with mean age 43.33 years, range between 25 to 75 years. Mean weight was 67.53 Kg range between 45 to $98 \mathrm{~kg}$ and mean height was 67 inches range between 52 to 72 inches. The mean duration of surgery was recorded as 85.33 minutes. Patients ASA I were $66.7 \%$ ASA II were $23.3 \%$ and ASA III were $10 \%$. Patients with comorbids like hypertension were 20.70 $\%$, chronic renal failure was $9.7 \%$ and Asthma were $3.30 \%$. Rest of $73.3 \%$ patients was fit without any comorbids. The height of block was recorded as; 15 patients with sensory block up to T6 level, 12 patients with sensory block up to T7 level and 3 patients with sensory block up to T8 level.
\end{abstract}

Conclusion: The spinal anaesthesia can be safely and effectively given to the adult patients undergoing PCNL.

Keywords: PCNL; Spinal anaesthesia; Adult patients

\section{Introduction}

Renal stones are one of the oldest entities known to mankind (eg. Egyptian mummies with renal stones) [1]. The reported incidence of stones in the urinary tract varies widely suggesting that there may be factors in the diet or water which favours stone formation in different areas the so called stone belts. Different modalities of treatment of renal calculi were being practiced. Pyelolithotomy, Nephrolithotomy were the important methods practiced for long times. Percutaneous Nephrolithotomy PCNL is now a popular method for removal of kidney and ureteral calculi and the treatment of choice for renal calculi greater than $2 \mathrm{~cm}$ to $3 \mathrm{~cm}$ in diameter, multiple kidney calculi, stag horn calculi and cases of failed shockwave lithotripsy (such as those with calcium oxalate monohydrate and cysteine calculi) [2,3]. PCNL is now established and popular method to treat renal calculi due to less trauma, early mobilization, less pain, less hospital stay and early returned to job makes it economical. Anaesthesia for PCNL can be general or regional [4].
The method of dilating the tract after percutaneous renal puncture to specifically remove urinary tract calculi was first established in 1976 by Fernstorm and Johansson [5]. Advances in surgical techniques and equipment have further contributed to PCNL becoming the recommended primary treatment option for most patients with large volume renal calculi and stag horn calculi [6]. In Korea the first PCNL was performed in July 1984 by Koh etal. [7]. The spinal anaesthesia is frequently used in obstetrics and many Gynecological surgeries as well as few cases of lumber Laminectomies [8]. PCNL is mostly performed under general anaesthesia but it can be performed under regional (Spinal) anaesthesia. Spinal anaesthesia has the advantages of better postoperative pain relief, fewer episodes of nausea and vomiting, more benign postoperative recovery, avoidance of poly pharmacy as well as being cost effective [9].

\section{Patients and Method}

This case series study was conducted at urology department 
Liaqat University Hospital Jamshoro during $1^{\text {st }}$ Nov 2013 to $31^{\text {st }}$ Oct 2014. Thirty male patients were selected for this study. Female patients were not included in this study due to social embracement, because patients remain awake in spinal anaesthesia during surgery. A formatted questionnaire was complete by one respondent. The questionare was designed to evaluate variables such as age, weight height of patient and status ASA I, II and III and duration of surgery were noted. (Table 1), Co-morbids (Figure 1), and supplemental drugs given (Table 2, Figure 2). Before anaesthesia and operation every patient was assessed properly, informed and written consent was taken. Standard monitors were applied, 18G i/v canula was inserted and all patients were preloaded with $500 \mathrm{ml}$ of colloid (Gelofusine). Intrathecal anaesthesia was administered in lateral position in L 3-4space with $0.75 \%$ hyperbaric Bupivacaine hydrochloride $2 \mathrm{ml}(15 \mathrm{mg})$. All anesthetic were performed with a 27 gauge Quincke-type spinal needle with introducer. The needle bevel was aligned parallel to the dural fibers. Patients were immediately placed supine with 10 degree head down tilt. Height of sensory block was assessed after 10 minutes (Table 3). Every patient was administered Injection Nalbuphine $5 \mathrm{mg}$ i/v after placing them prone. Patients oxygen saturation, heart rate, systolic and diastolic blood pressures were noted every 10 minutes throughout the surgery (Figure 3). Sedation in form of Propofol infusion $25 \mathrm{mg} / \mathrm{Kg} / \mathrm{min}$ and analgesia in the form of Ketamine $20 \mathrm{mg}$ boluses were provided accordingly. Hypotension was treated with Ephedrine $5 \mathrm{mg}$ boluses.
Table 1: Demographic characteristics.

\begin{tabular}{|c|c|c|}
\hline & Mean \pm SD $/ \%$ & Range \\
\hline Age (yrs) & $43.33 \pm 12.39$ & $25-70$ \\
\hline Wt (kg) & $67.53 \pm 10.24$ & $45-98$ \\
\hline Ht (inches) & $67 \pm 3.31$ & $52-72$ \\
\hline Gender male \% & 100 & \\
\hline ASA-I (\%) & 66.7 & \\
\hline ASA-II & 23.3 & \\
\hline ASA-III & 10 & \\
\hline SaO2 \% & 99 & \\
\hline Duration of surgery min & $85.33 \pm 14.4$ & $40-140$ \\
\hline
\end{tabular}

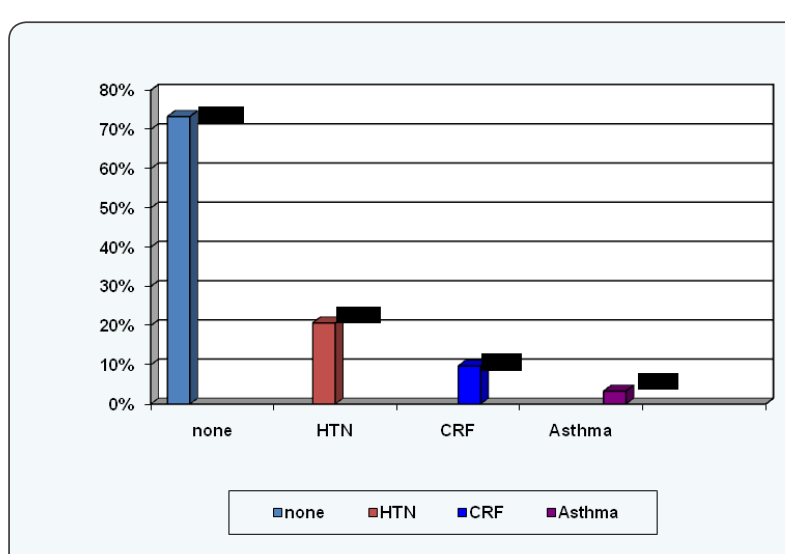

Figure 1: Demographic characteristics.

Table 2: Haemodynamics during surgery.

\begin{tabular}{|c|c|c|c|c|c|c|c|c|}
\hline & B-line & $\mathbf{5}$ min & $\mathbf{1 0}$ min & $\mathbf{2 0 m i n}$ & $\mathbf{3 0}$ min & $\mathbf{4 0 m i n}$ & $\mathbf{5 0 m i n}$ & $\mathbf{6 0 m i n}$ \\
\hline SBP & $132.24 \pm 4.5$ & $126.83 \pm 19.6$ & $120.03 \pm 16$. & $116.57 \pm 11.1$ & $118.53 \pm 9.7$ & $115.93 \pm 10.4$ & $118.8 \pm 9.89$ & $121.4 \pm 10.46$ \\
\hline DBP & $79.65 \pm 6.67$ & $78.2 \pm 11.2$ & $72.67 \pm 6.68$ & $72.67 \pm 6.68$ & $72.23 \pm 7.26$ & $71.47 \pm 6.23$ & $75.03 \pm 7.2$ & $74 \pm 8.08$ \\
\hline HR & $74.56 \pm 8.11$ & $81.83 \pm 13.8$ & $76.4 \pm 11.77$ & $74.07 \pm 7.74$ & $75.07 \pm 7.25$ & $73.67 \pm 7.27$ & $74.4 \pm 6.76$ & $77 \pm 7.16$ \\
\hline
\end{tabular}

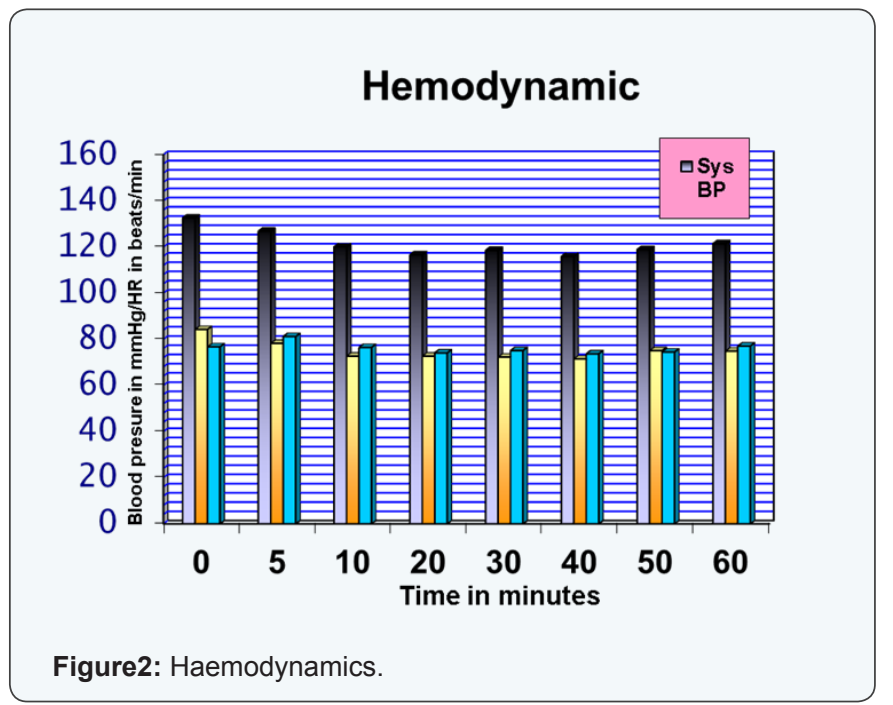

\section{Results}

This study conducted on 30 male patients with median age 43.33 range 25 to 75 years, median weight $67.53 \mathrm{Kg}$ range 45 to $98 \mathrm{Kg}$, median height 67 inches range 52 to 72 inches. Anesthesia assessment was made as ASA I 20 patients i-e 66.7 $\%$ ASA II 7 patients i-e $23.3 \%$ and ASA III 3 patients i-e $10 \%$. $\mathrm{SO}_{2}$ saturation was maintained at $99 \%$. Duration of surgery was recorded as 85.33 minutes range 40-140 minutes (Table 1). Out of these thirty patients 22 patients i-e $73.30 \%$ did not had any comorbids, 7 patients i-e $20.70 \%$ patients were hypertensive and 3 patients $9.70 \%$ were suffering from chronic renal failure with renal stones and 1 patient i-e $3.30 \%$ was asthmatic (Figure 1).

The haemodynamics during surgery were mentained and noted. The mean baseline systolic Blood pressure was recorded 
as $132.24 \pm 4.5$ and mean diastolic baseline blood pressure was recorded as $79.65 \pm 6.67$ and mean heart rate was $74.56 \pm 8.11$. Blood pressure and heart rate were noted at 5 minutes, 10 minutes, 20 minutes, 30 minutes, 40 minutes, 50 minutes, 60 minutes duration in each patient and recorded, the mean value was calculated and given in Table 2, Figure 2. Propofol was given to 10 i-e $33.3 \%$ patients and ketamine was needed in 5 i-e $16.7 \%$ patients while only 3 i-e $10 \%$ patients needed Ephedrine (vasopressor) to maintain their blood pressure (Table 3). 15 i-e $50 \%$ patients received sensory block up to T6 level, 12 i-e $40 \%$ patients received block up to T7 level and remaining 3 i-e10\% patients received block up to teen age level (Figure 3).

Table 3: Supplemental Drugs.

\begin{tabular}{|c|c|c|}
\hline & \% Received & \% Not Received \\
\hline Sedation Propofol & 33.3 & 66.7 \\
\hline Analgesia Ketamine & 16.7 & 83.3 \\
\hline $\begin{array}{c}\text { Vasopressor } \\
\text { Ephedrine }\end{array}$ & 10 & 90 \\
\hline
\end{tabular}

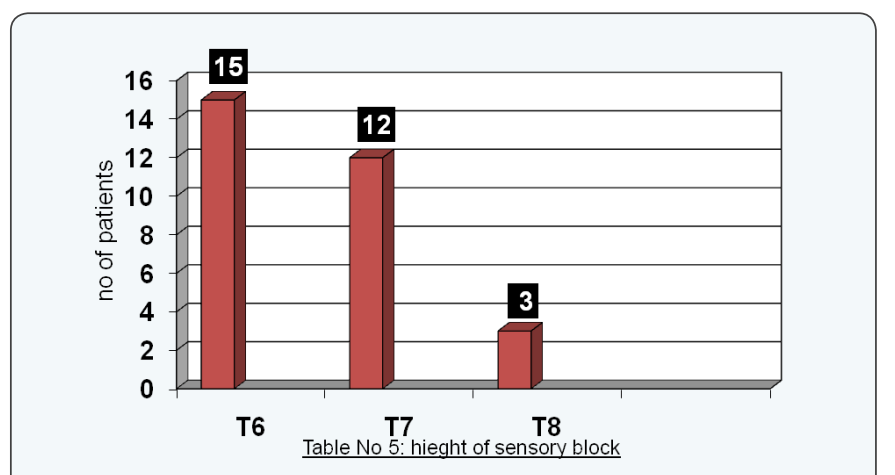

Figure 3: Height of sensory block.

\section{Discussion}

Percutaneous Nephrolithotomy (PCNL) is a minimally invasive effective and safe modality for removal of renal and upper ureteric calculi. Percutaneous Nephrolithotomy is used for the fragmentation and removal of large or multiple calculi from the renal pelvis and renal caliceal systems [10]. It has been shown that PCNL under assisted local anaesthesia is safe and effective in selected patients [11]. It has the advantage of shorter operative time, shorter hospital stay, and earlier return to work [12]. Anaesthesia for PCNL can be general or regional [4]. Spinal anaesthesia is not without complications but the complications are preventable [13]. Several studies have shown that spinal anaesthesia results in less intra-operative bleeding compared with general anaesthesia $[14,15]$. The spinal anaesthesia has the advantages of better postoperative pain relief, fewer episodes of nausea and vomiting, more benign postoperative recovery, avoidance of polypharmacy as well as being cost effective [9]. Spinal anaesthesia with bupivacaine is reportedly efficacious and safe [14].
In 321 cases of orthopedic and trauma surgery Ramaioli and Pagani [15] found that $10 \mathrm{mg}$ of $1 \%$ bupivacaine without adrenaline provided 135 minutes of spinal anaesthesia for hip and femur operations. In our study we had injected $0.75 \%$ hyperbaric bupivacaine $2 \mathrm{ml}(15 \mathrm{ml})$ in every patient. The duration of surgery was recorded as 85.33 minutes range 40 to 140 minutes (Table 1 ) and found to be adequate. The haemodynamics of these patients showed stable systolic and diastolic blood pressure and heart rate (Table 2, Figure 2). Only $10 \%$ patients needed Ephedrine (vasopressor) (Table 3). The height and quality of block was adequate for PCNL in all patients (Figure 3). It has been shown that PCNL under assisted local anaesthesia is safe and effective in selected patients ${ }^{[11]}$. General anaesthesia can be challenged in some situations such as PCNL for stag horn calculi because of possibility of fluid absorption and electrolyte imbalance. Therefore regional anaesthesia may be a good alternative [16]. Thus common complications of the general anaesthesia such as sore throat, presser response to laryngoscopy and intubation, bronchospasm, laryngospasm as well as postoperative nausea and vomiting are avoided which ultimately leads to shorter hospital stay.

\section{References}

1. Sami-Ullah, Chaudary AI, Masood R (2007) A Comparison of open vesicolithotomy and cystolithotomy. Pak J Med Sci 23(1): 47-50.

2. Wong MY (1998) Evolving technique of percutaneous nephrolithotomy in a developing country: Singapore General Hospital experience. J Endourol 12(5): 397-401.

3. Basiri A, Mehrabi S, Kianian H, Javaherforooshzadeh A (2007) Blind puncture incomparison with fluoroscopicguidance in percutaneous nephrolithotomy: a randomized controlled trial. Urol J 4(2): 79-83.

4. Mehrabi S, Karimzadeh SK (2010) Results and complications of spinal anaesthesia in Percutaneous Nephrolithotomy. Urol J 7(1): 22-25.

5. Fernstorm I, Johansson B (1976) Percutaneous Pyelolithotomy A new extraction technique. Scand J; urolNephrol 10(3): 257-259.

6. Preminger GM, Assimos DG, Lingeman JE, Nakada SY, Paerle MS et al. (2005) AUA. Nephrolithiasis guideline panel chapter 1: AUA guideline on management of staghorn calculi: diagnosis and treatment recommendations. J Urol 173(6): 1991-2000.

7. Koh Sk, Cho JP, Yoon DK, Cha IH (1984) Percutaneous Nephrolithotripsy. Korean J urol 25: 739-745.

8. Hussain N, Tayab S, Mahmood T (2000) Spinal Anaesthesia for caesarean Section. J Surg Pak 7: 19-20.

9. Haider S, Sultan ST (2000) Interthecal anesthesia for transurethral resection of prostate. Our experiences at Civil Hospital Karachi. Spectrum 21: 10-13.

10. Burns SM, Cowan CM, Wilkes RG (2001) Prevention and management of hypotension during spinal anaesthesia for elective caesarean section: a survey of practice. Anaesthesia 56(8): 794-798.

11. McLain RF, Bell GR, Kalfas I, Tetzlaff JE, Yoon HJ (1976) Complications associated with lumbar laminectomy: a comparison of spinal versus general anaesthesia. Spine 29(22): 2542-2547.

12. Khan S, Toori LA, Anwar K (2005) The efficiency of PCNL in renal and upper ureteric caculi. Pak J Med Res.

13. Stoller ML, Lee KL, Schwartz BF, Viele MK (1999) Autologous blood use 
in percutaneous nephrolithotomy. Urology 54(3): 444-449.

14. Montamat SC, Cusack BJ, Vestal RE (1989) Management of drug therapy in the elderly. N Engl J Med 321(5): 303-309.

15. Aravantinos E, Karatzas A, Gravas S, TzortzisV, Melekos M (2007) Feasibility of percutaneous nephrolithotomy under assisted local anaesthesia: a prospective study on selected patients with upper urinary tract obstruction. Eur Urol 51(1): 224-7.

16. Corbel L, Guille F, Cipolla B, Staerman F, Leveque JM, et al. (1993) [Percutaneous surgery for lithiasis :results and perspectives. Apropos of 390 operations]. Prog Urol 3(4): 658-665. 